This is an author produced version of a paper published in Oecologia.

This paper has been peer-reviewed but may not include the final publisher proof-corrections or pagination.

Citation for the published paper:

David G. Angeler; Didier L. Baho; Craig R. Allen; Richard K. Johnson. (2015) Linking degradation status with ecosystem vulnerability to environmental change. Oecologia. Volume: 178, Number: 3, pp 899-913.

http://dx.doi.org/10.1007/s00442-015-3281-y.

Access to the published version may require journal subscription.

Published with permission from: Springer Verlag.

Standard set statement from the publisher:

The finalpublication is available at link.springer.com

Epsilon Open Archive http://epsilon.slu.se 


\section{Linking degradation status with ecosystem vulnerability to environmental change ${ }^{1}$}

4 David G. Angeler ${ }^{1}$, Didier L. Baho ${ }^{1}$, Craig R. Allen ${ }^{2}$, and Richard K. Johnson ${ }^{1}$

$6 \quad{ }^{1}$ Swedish University of Agricultural Sciences, Department of Aquatic Sciences and

7 Assessment, PO Box 7050, SE - 75007 Uppsala, Sweden

8

$9 \quad{ }^{2}$ U.S. Geological Survey, Nebraska Cooperative Fish and Wildlife Research Unit, School of Natural

10 Resources, University of Nebraska - Lincoln, Lincoln, NE, USA.

11

12 *author for correspondence:

13 david.angeler@slu.se

14 Tel: +46 (0) 18-673049

15 Fax: +46 (0) 18-673156

16

17

18

19 Running head: degradation, vulnerability and resilience

\footnotetext{
${ }^{1}$ Author contributions: All authors conceived and wrote the paper, DGA and DLB analyzed the data.
} 


\section{Abstract}

21 Environmental change can cause regime shifts in ecosystems, potentially threatening ecosystem

22 services. It is unclear if the degradation status of ecosystems correlates with their vulnerability to

23 environmental change, and thus the risk of future regime shifts. We assessed resilience in acidified

24 (degraded) and circum-neutral (undegraded) lakes with long-term data (1988-2012), using time series

25 modeling. We identified temporal frequencies in invertebrate assemblages, which identifies groups of

26 species whose population dynamics vary at particular temporal scales. We also assessed species with

27 stochastic dynamics, those whose population dynamics vary irregularly and unpredictably over time.

28 We determined the distribution of functional feeding groups of invertebrates within and across the

29 temporal scales identified, and in those species with stochastic dynamics, and assessed attributes

30 hypothesized to contribute to resilience. Three patterns of temporal dynamics, consistent across study

31 lakes, were identified in the invertebrates. The first pattern was one of monotonic change associated

32 with changing abiotic lake conditions. The second and third patterns appeared unrelated to the

33 environmental changes we monitored. Acidified and the circum-neutral lakes shared similar levels

34 and patterns of functional richness, evenness, diversity, and redundancy for species within and across

35 the observed temporal scales and for stochastic species groups. These similar resilience

36 characteristics suggest that both lake types did not differ in vulnerability to the environmental

37 changes observed here. Although both lake types appeared equally vulnerable in this study, our

38 approach demonstrates how assessing systemic vulnerability by quantifying ecological resilience can

39 help address uncertainty in predicting ecosystem responses to environmental change across

40 ecosystems.

42 Key words: environmental change, benthic invertebrates, functional redundancy, scales,

43 vulnerability, time series modeling, resilience, functional traits 


\section{Introduction}

45 Human activity (e.g. overfishing, eutrophication, acidification, global warming) can cause

46 catastrophic regime shifts of ecosystems (e.g. Hirota et al. 2011; Kosten et al. 2012). Increasing

47 pressures from growing human populations will likely continue to push ecosystems beyond their

48 capacity to cope with stress. Consequently, increasing incidences and magnitudes of regime shifts in

49 the future will likely trigger complex social-ecological responses that can transcend scales from local

50 to regional to global (Barnosky et al. 2012; Hughes et al. 2013).

51 Environmental degradation impacts biodiversity, contributes to the extinction of sensitive

52 species and potentially jeopardizes the provisioning of ecosystem services (Hooper et al. 2005). The

53 loss of species, combined with other alterations of structural and functional community attributes

54 with increasing degradation, has been linked to a decrease in ecosystem resilience (Peterson et al.

55 1998; Folke et al. 2004; Fischer et al. 2006). If these community changes increase the vulnerability to

56 environmental change stressors, manifested in decreasing resilience, it can be assumed that degraded

57 ecosystems will become more prone to regime shifts than undegraded ecosystems. Therefore, it is

58 necessary to quantify vulnerability at the ecosystem level to assess the likelihood of regime shifts,

59 and to inform management actions that might serve to prevent regime shifts (Angeler et al. 2014). In

60 this paper we test for ecosystem vulnerability by quantifying patterns of richness and function at

61 discrete temporal scales in lakes that have been affected by differential degrees of anthropogenic

62 acidification.

63 Acidification of surface waters was a severe environmental problem in Europe and North

64 America during the 1970 - 1980s, causing biodiversity loss and altering ecosystem processes

65 (Schindler 1988). International policy was enacted to reduce the emissions of nitrogen oxide and

66 sulfur dioxide to protect and restore natural resources (Stoddard et al. 1999). However, despite

67 reduced acid deposition contributing to chemical recovery of surface waters, empirical evidence of

68 biological recovery (i.e., a return to ecological conditions prior to acidification) has been equivocal 
69 (Skjelkvåle et al. 2003; Ormerod and Durance 2009). Thus, the failure to meet biological recovery

70 goals means that acidification is still considered a critical problem affecting the biodiversity and

71 ecosystem service provisioning of inland surface waters in northern Europe (Johnson and Angeler

72 2010) and elsewhere (Burns et al. 2008; Batterbee et al. 2014). Furthermore, the combined effects of

73 alterations in land use, catchment hydrology, acid deposition rates, and climatic change trigger

74 similar patterns of ecological change in lakes independent of their acidification status. These changes

75 occur in the form of regionally decreasing water clarity and ion concentrations, the range expansion

76 of nuisance species and changing biodiversity patterns across boreal lakes (Burgmer et al. 2007;

77 Angeler and Johnson 2012; Angeler et al. 2012; Trigal et al. 2013). Lakes can undergo regime shifts

78 triggered by acidification or eutrophication (Scheffer and Carpenter 2003; Baho et al. 2014). Because

79 it is currently unclear whether the environmental changes observed will erode resilience to eventually

80 cause a regime shift of boreal lakes it is necessary to assess vulnerability, and determine if

81 vulnerability differs between lakes of different degradation status.

82 In this paper, we compare the vulnerability of acidified lakes with those of near-pristine,

83 undegraded, circum-neutral lakes that comprise targeted management references for acidified lakes

84 (Yan et al. 1996). We assess vulnerability from a systemic perspective in both acidified and circum-

85 neutral lakes; that is, we quantify attributes that have been considered important for mediating the

86 ecological resilience of ecosystems (sensu Holling 1973). Ecological resilience is the amount of

87 disturbance an ecosystem can tolerate before shifting into an alternative state with a different set of

88 processes and structures relative to those present in the state before the shift. Ecological resilience is

89 a broad concept, focused on the dynamics of complex adaptive systems (e.g. ecosystems). The

90 definition therefore integrates other concepts related to ecological stability, such as resistance

91 (Walker et al. 2004), and differs from engineering resilience which focuses on the time needed to

92 recover to predisturbed conditions (Pimm 1991).

93 Central to ecological resilience theory is that structures, functions and processes are 
94 regulated by a few variables that operate at characteristic temporal and spatial scales (Allen et al.

95 2014; Nash et al. 2014). To account for scale, the cross-scale resilience model was developed to

96 empirically quantify ecological resilience (Peterson et al. 1998). In this model resilience is assessed

97 through quantification of functional traits and their distribution within and across scales of space and

98 time (Fischer et al. 2007; Sundstrom et al. 2012). Resilience is hypothesized to increase 1) with an

99 increased redundancy and diversity of ecological function among species that operate at the same

100 spatial or temporal scale (within-scale redundancy), 2) with a redundancy of function across these

101 scales in a system (cross-scale redundancy) (Allen et al. 2005), and 3) with different responses to

102 disturbance by species within the same functional group and scale (response diversity; Elmqvist et al.

103 2003). An assessment of within and cross-scale redundancy of function allows a quantitative

104 measure of relative resilience (Peterson et al. 1998).

105 Tools have been developed that allow quantification and comparison of dominant scales of

106 processes and structures that are present in a system (Stow et al. 2007; Nash et al. 2014). Here we use

107 multivariate time series modeling to identify different temporal frequency patterns in the abundance

108 of littoral invertebrate communities. This tool has been recently used in several studies of resilience

109 (e.g. Angeler et al. 2011; Angeler et al. 2013ab; Baho et al. 2014). Specifically, we test for the

110 presence of temporal patterns in the abundance of littoral invertebrate species and the prevailing

111 frequencies of these patterns. Discrete frequencies are used to infer dominant temporal scales in the

112 community dynamics. Next, we focus on the invertebrate taxa associated with the temporal scales

113 identified and evaluate their functional attributes. Invertebrate taxa have a variety of feeding modes

114 (predators, shredders, grazers, gatherer-collectors, filterers) and are therefore important for different

115 ecosystem functions, including nutrient cycling and matter fluxes, leaf litter processing, and

116 secondary production (e.g. Covich et al. 1999).

117 In addition to quantifying temporal patterns, time series modeling allows for the detection of 118 species with stochastic dynamics; that is, those species (that are often uncommon) whose population 
119 dynamics vary irregularly and unpredictably over time. Although stochastic species do not contribute

120 to within and cross-scale patterns in a system, they comprise an important component for resilience

121 (Baho et al. 2014). For instance, when environmental conditions change, stochastic species may

122 become abundant, potentially substituting for species that went extinct, and therefore contribute to

123 the maintenance of ecosystem processes and stability (Walker et al. 1999; Carpenter et al. 2001). The

124 ability to maintain processes while ecosystems undergo change can be defined as adaptive capacity

125 (Carpenter et al. 2001). Thus, both the distribution of functions within and across scales identified

126 and the adaptive capacity that rests in the stochastic group of species are critical for the maintenance

127 of resilient ecosystems.

128 Assessing the vulnerability of ecosystems based on resilience concepts has clear relevance

129 both for management and conservation, as well as for refining ecological theory. If species that are

130 sensitive to stress such as acidification are lost from the system, reduced biodiversity may result in

131 lower within and cross-scale redundancy under degraded ecosystem conditions, relative to higher

132 diversity states of near-pristine ecosystems. Stress could be further manifested in lower functional

133 richness, diversity and redundancy in groups of species with stochastic dynamics, thereby reducing

134 adaptive capacity to respond to further environmental stress. Lower diversity of functional attributes

135 and lower abundance of species with certain functional attributes, could increase vulnerability to

136 regime shifts. Here we test this conjecture using acidified lakes as models of degraded ecosystems.

137 We identify temporal scales in invertebrate communities with time series modeling, and compare the

138 patterns of functional attributes in invertebrate species within and across the identified scales. We

139 compare the patterns identified in acidified lakes with those in circum-neutral reference lakes to

140 assess if the acidified lakes appear more vulnerable to environmental change. 


\section{Material and Methods}

\section{Study area}

145 Sweden began a long-term lake monitoring program in multiple habitats and across trophic levels to

146 follow the effects of anthropogenic acidification of regionally representative lakes in relation to lakes

147 with a higher acid neutralizing capacity (Johnson 1999). Twelve lakes with monitoring data for water

148 quality and littoral invertebrate communities were chosen for this study, and provided data for the

149 period 1988 to 2012. Six lakes were culturally acidified and six lakes were circum-neutral, based on

150 biogeochemical modeling criteria (Fölster et al. 2007). Biogeochemical modeling estimates the

151 changes in buffering capacity between preindustrial periods and the present, and calculates changes

152 in $\mathrm{pH}$ between these periods. A lake is considered acidified if $0.4 \mathrm{pH}$ units between periods are

153 exceeded. Information regarding the monitoring program can be found in Fölster et al. (2014) and at:

154 http://www.slu.se/en/faculties/nl/about-the140faculty/departments/department-of-aquatic-sciences-

155 and-assessment/data-host/. Selected environmental variables and the geographical coordinates of

156 these lakes are provided in Electronic Supplementary Material.

\section{Sampling}

159 Sampling and analyses of abiotic and biological variables was based on standard protocols

160 throughout the study. These protocols are quality controlled and certified by the Swedish Board for

161 Accreditation and Conformity Assessment (SWEDAC; http://www.swedac.se/en/). Surface samples

162 for physicochemical analyses (taken at $0.5 \mathrm{~m}$ depth) were collected with a Plexiglas sampler four to

163 eight times each year at a mid-lake station in each lake and kept cool during transport to the

164 laboratory. Samples were analyzed for acidity ( $\mathrm{pH}$, alkalinity, $\mathrm{SO}_{4}{ }^{2-}$ concentration), nutrients (total $\mathrm{P}$,

165 phosphate, total N, Ca), water clarity (Secchi disc depth, water color, total organic carbon), and ionic

166 strength (electrical conductivity). The analyses were conducted at the Department of Aquatic

167 Sciences and Assessment complying with international (ISO) or European (EN) standards (Fölster et 
168 al. 2014). Measurement intervals and uncertainties for each variable can be found at:

169 http://www.slu.se/en/faculties/nl/about-the-faculty/departments/department-of-aquaticsciences-and-

170 assessment/laboratories/geochemical-laboratory/water-chemical-analyses/.

171 Invertebrate sampling adhered to Swedish standards (SS-EN 27828). Briefly, five replicate

172 samples were taken using standardized kick sampling with a hand net (0.5 mm mesh size) from one

173 wind-exposed, vegetation-free littoral habitat in late autumn (end of October to early November each

174 year) in each lake. Sampling consisted of disturbing the substratum along a $1 \mathrm{~m}$ long stretch for 20

175 seconds in the littoral region at a depth of c. $0.5 \mathrm{~m}$. Samples were immediately preserved in 70\%

176 ethanol and later processed in the laboratory by sorting against a white background with 10x

177 magnification. Invertebrates were sorted, identified to the lowest feasible taxonomic unit and counted

178 using light and dissecting microscopes. The same person, a trained taxonomist, has evaluated all

179 samples throughout our study.

180

181 Statistical analyses

182 Time series modeling - Time series of multispecies assemblages can show a wide range of temporal

183 patterns in species occurrence and abundance, including monotonic, stochastic and cyclic patterns,

184 the latter occurring at distinct frequencies. Here we use a method that objectively identifies temporal

185 patterns that are inherent in time series of ecological communities. Because it is able to identify

186 fluctuation frequencies at different temporal scales (e.g. decadal, annual, seasonal), the method has

187 been useful for assessing resilience (Angeler et al. 2014; Baho et al. 2014). The method is based on

188 redundancy analysis (RDA) (Angeler et al. 2009), and uses temporal variables extracted by AEM

189 analysis (Asymmetric Eigenvector Maps, Blanchet et al. 2008). Details of all steps in the analyses are

190 in Electronic Supplementary Material. The approach can be summarized as follows:

191 1) The AEM analysis creates the temporal variables necessary for extracting distinct temporal

192 patterns from the data set. This is accomplished by converting the linear time vector that comprises 
193 the sampling frequency and length of the study period into a set of orthogonal temporal variables. In

194 our study, these variables correspond to a specific temporal structure and scale in the invertebrate

195 community. That is, the first AEM variable models linear trends and the subsequent variables capture

196 temporal variability from slow to increasingly shorter fluctuation frequencies in the community data

197 over the study period. The scales of pattern and structure that can be discerned have upper bounds set

198 by the limit of the temporal extent of the data series, and lower bounds set by the frequency of

199 sample collection. Accordingly, in our study the shortest fluctuation frequency captures yearly

200 variation because invertebrates have been sampled once per year and the temporal extent consisted of

20125 equidistant time steps (in years) between 1988-2012. The AEM analysis thus yielded 8 variables

202 with positive eigenvalues from the conversion of the linear time vector.

203

204 2) For each lake, we constructed a parsimonious RDA model for invertebrate community dynamics

205 by running a forward selection on these 8 AEM variables. Because AEM analysis is efficient in

206 covering linear trends no detrending of models was necessary. The RDA retains significant AEM

207 variables and these are linearly combined to extract temporal patterns from the Hellinger-transformed

208 species matrices; that is, the RDA identifies species with similar temporal patterns in the species $\mathrm{x}$

209 time matrix and uses their temporal patterns to calculate a modeled species group trend for these

210 species based on linearly combined AEMs. The significance of the temporal patterns of all modeled

211 species groups revealed by the RDA is tested by means of permutation tests. The RDA relates each

212 modeled temporal fluctuation pattern with a significant canonical axis. The R software generates

213 linear combination (lc) score plots, which visually present the modeled fit of temporal patterns of

214 species groups that are associated with each canonical axis.

215

216 3) The modeling results provide insight into resilience. Canonical axes are orthogonal (independent

217 from each other) and thus can be used to assess the number of temporal patterns/scales representing 
218 community dynamics. In the context of resilience cross-scale community dynamics were quantified

219 by counting the number of significant canonical axes in the RDA models, while within-scale of

220 resilience was determined by quantifying species correlations with the temporal pattern of each

221 significant canonical axis in the model (see below).

222 All relevant steps in the analyses were carried out with two functions implemented in R

223 2.15.1 statistical software package (R Development Core Team 2012). First, the conversion of the

224 linear time vector to AEM variables was done using the "aem.time” function (AEM package). This

225 function accounts for the connectivity of linear time steps. Thus, a connectivity matrix required in

226 spatial analysis with hierarchical or dendritic designs is not necessary in time series analysis. The

227 remaining modeling steps (calculation of modeled species group trends, visual presentation of the

228 results in form of lc score plots) were carried out with the "quickPCNM” function (PCNM package).

230 Abiotic and biotic correlates of modeled temporal patterns - We aimed to identify the

231 environmental correlates of the temporal pattern of invertebrates found for each significant canonical

232 axis of the RDA models. We used Spearman rank correlation analyses to correlate modeled lc scores

233 with yearly-averaged water quality data. We also used Spearman rank correlation analyses to relate

234 the raw abundance data of individual invertebrate taxa with the modeled lc scores from the RDA

235 models. This helped evaluate the within-scale aspect of resilience. We also evaluated the number of

236 species with presumably stochastic dynamics (that is, species that were not associated with any

237 significant canonical axis). We subtracted the sum of species that correlated with canonical axes from 238 the total number of species present in each lake (Baho et al. 2014).

239 In our resilience assessment, we used taxa that were identified to species and morphotypes

240 that could be classified into functional feeding groups for further analysis. Taxa with only higher

241 taxonomic level resolution (family and above) were not included to avoid influencing the analyses

242 through ambiguous feeding group assignments. Taxa that correlated with modeled temporal patterns 
243 and stochastic dynamics were classified into filterers, gatherers, grazers, omnivores, shredders and

244 predators, based on scores between 1 and 10, with 10 indicating highest feeding preference. The

245 online data base www.freshwaterecology.info (Schmidt-Kloiber and Hering 2012) was used for

246 scoring feeding group traits. Omnivores were comprised of taxa that scored identically among

247 different feeding groups, here mostly gatherers and grazers. We also assessed acid-sensitivity of

248 species following Angeler and Johnson (2012) and the Red List status of the identified taxa for

249 Sweden using the same online database.

250

251 Functional community attributes and resilience assessment - We calculated two measures that have

252 been used to infer resilience following the cross-scale resilience model: 1) Within-scale redundancy

253 (the average number of species within each functional group at each temporal pattern; Allen et al.

254 2005), and 2) Cross-scale redundancy (the average number of temporal frequency scales at which

255 each function is represented; Allen et al. 2005). To allow for a broader characterization of resilience

256 we calculated additional measures: 3) Functional richness (the number of feeding groups present). 4)

257 Functional diversity based on the exponentiated Shannon-Wiener index (exp H') that accounts for

258 both the presence of feeding groups and the number of species that belong to a feeding group.

259 Exponentiation of H’ makes richness and diversity data directly comparable (Jost 2007; Tuomisto

260 2010). 5) Functional evenness calculated as the quotient between functional diversity and functional

261 richness. This calculation makes evenness independent from richness (Tuomisto 2012). In addition to

262 these functional measures, we calculated two structural community metrics (total taxon richness and

263 the richness of acid-sensitive taxa). All measures were calculated for each temporal frequency scale

264 (significant canonical axes in RDA models) and the stochastic pattern of each lake. Note that these

265 measures are calculated from the modeling results (species and their functional feeding guild

266 attributes associated with canonical axes and the stochastic group of species). This enabled the

267 characterization of structural and functional characteristics for the distinct temporal patterns 
268 identified, although the approach does not identify temporal trends in these measures per se.

270 Statistical comparisons - Kendall's tau rank correlations, a nonparametric test of concordance, was

271 used to explore patterns of monotonic change of water chemistry variables over the study period. We

272 used two-way ANOVAs to test for significant differences in the distribution of metrics (taxon

273 richness, richness of acid-sensitive taxa, functional richness, functional diversity, functional

274 evenness, average within-scale redundancy) between acidified and circum-neutral lakes. These

275 metrics comprised the dependent variables and lake type (circum-neutral, acidified; fixed factor) and

276 temporal pattern (temporal frequencies associated with RDA 1 - RDA 3 and stochastic patterns; fixed

277 factor) comprised the independent variables. Note that no comparisons were made for a fourth

278 pattern (RDA 4) because such a pattern was found only in a few lakes. In a second ANOVA, we also

279 examined whether within-scale redundancy at each temporal scale and the cross-scale redundancy

280 between these scales varies as a function of lake type and functional feeding group. In this analysis

281 within-scale redundancy associated with all temporal patterns and the cross-scale redundancy

282 comprised the dependent variables and functional feeding groups the independent variables. When a

283 significant main effect was detected, a posteriori comparisons were made using the Tukey HSD test.

284 Univariate comparisons were complemented with multivariate analyses using non-metric

285 multidimensional scaling (NMDS) in Primer 6 (Primer-E Ltd, Plymouth, UK) of Bray-Curtis

286 transformed similarity matrices on square-root transformed data (999 re-runs). NMDS was followed

287 by permutational multivariate ANOVA (PERMANOVA) to contrast multivariate invertebrate

288 functional attributes between lake types (circum-neutral vs acidified lakes, fixed factor) and temporal

289 patterns (RDA 1 vs RDA 2 vs RDA 3 vs stochastic, fixed factor). PERMANOVAs were calculated

290 on Bray-Curtis and Sorensen similarity matrices of square-root transformed species data (9999

291 unrestricted permutations of raw data) using PERMANOVA v1.6 (Anderson 2005).

292 For both univariate and multivariate comparisons, we consider interaction terms crucial for 
293 inference. If the interactions are significant, we conclude that the relative resilience of one lake type,

294 based on the structure and distribution of functions within and across temporal patterns, differs

295 significantly from the other lake type. In turn, this indicates that one lake type is potentially more

296 vulnerable to environmental change relative to the other lake type.

\section{Results}

299 Temporal patterns and trends of environmental variables

300 The patterns of temporal change in water quality variables were generally congruent between circum-

301 neutral and acidified lakes (Fig. 1). pH increased significantly over time in both lake types (acidified

302 lakes: Kendall's tau $=0.61, \mathrm{P}<0.001$; circum-neutral: Kendall's tau $=0.47, \mathrm{P}=0.001$ ), but remained

$303<6$ in acidified lakes throughout the study, indicating that chemical recovery was weak (Fig. 1A).

304 Alkalinity increased in circum-neutral (Kendall's tau $=0.65, \mathrm{P}<0.001$ ) but not in acidified lakes (P

$305>0.05$ ) (Fig. 1B). Sulfate concentrations decreased monotonically in both lake types (acidified lakes:

306 Kendall's tau $=-0.82, \mathrm{P}<0.001$; circum-neutral: Kendall's tau $=-0.97, \mathrm{P}<0.001)$ (Fig. 1C).

307 Concomitant with changes in acidity, we observed a gradual change in water clarity over the study

308 period, manifested as a significant decrease in Secchi transparency (acidified and circum-neutral:

309 Kendall's tau $=-0.81, \mathrm{P}<0.001$ ), and increase in water color (acidified: Kendall's tau $=0.70, \mathrm{P}<$

310 0.001; circum-neutral: Kendall's tau $=0.67, \mathrm{P}<0.001$ ) and total organic carbon (acidified: Kendall’s

311 tau $=0.67, \mathrm{P}<0.001$; circum-neutral: Kendall's tau $=0.59, \mathrm{P}<0.001$ ) in both lake types (Fig. 1D-F).

312 Water temperature and nutrients (TP, $\left.\mathrm{PO}_{4}, \mathrm{TN}\right)$ fluctuated around a long-term mean (P > 0.05; Fig.

313 1G, J-L), while electrical conductivity (acidified: Kendall's tau = -0.66, P < 0.001; circum-neutral:

314 Kendall's tau $=-0.74, \mathrm{P}<0.001$ ) and Ca concentrations (acidified: Kendall's tau $=-0.73, \mathrm{P}<0.001$;

315 circum-neutral: Kendall's tau $=-0.83, \mathrm{P}<0.001$ ) decreased significantly through time in both lake

316 types (Fig. 1H, I). 
319 Analyzing invertebrate communities with the RDA-AEM approach revealed significant temporal

320 patterns in all of the twelve lakes between 1988 and 2012. Significant temporal patterns were

321 associated with three canonical axes in the RDA models for most lakes, indicating that species

322 groups of invertebrates reflect three distinct temporal frequencies or scales (Fig. 2). In a few lakes

323 (Humsjön, Harasjön, Storasjö), a fourth temporal pattern was identified (Fig. 2D, I, L). The first

324 frequency pattern explained between $17 \%$ and $30 \%$ of the adjusted variance across all lakes in the

325 constrained models; the second, third and fourth patterns explained between $8 \%$ and $16 \%$, 5\% and

$32610 \%$, and $4 \%$ and $6 \%$ of the adjusted variance in all invertebrate communities across lakes,

327 respectively.

328 The first temporal frequency of invertebrate species groups generally showed components of

329 monotonic change combined with sine-wave properties in both lake types (blue lines in Fig. 2A-L).

330 These patterns cover temporal dynamics that were associated mainly with slow changes in acidity

331 and water clarity over the 25-year study period (Electronic Supplementary Material). We therefore

332 refer to this first temporal frequency group of invertebrates as "slow groups" that track these slower

333 changes in the environment. The second and third frequency of species groups showed shorter-term

334 periodicity at roughly 10-year and 5-year intervals (red and green lines in Fig. 2A-L), and although

335 these groups did not show any consistent correlations with the studied environmental variables

336 (Electronic Supplementary Material), they presumably track faster ecological processes. These

337 groups are therefore referred to as “intermediate groups” and “faster groups”. When a fourth

338 frequency patterns was detected, it showed species fluctuations at temporal scales that were

339 intermediate to those resolved by the first three patterns. Because only a few lakes showed this

340 pattern, limiting comparison, we did not use these for the ANOVA analyses of metrics, although

341 these patterns were considered for calculating average within and cross-scale redundancy. 
344 From the 353 invertebrate taxa present in our data set 65 were classified as acid-sensitive and none

345 was red-listed for Sweden. The distribution of both sensitive and tolerant species among the slow,

346 intermediate, and faster groups was highly variable between lakes (see Angeler and Johnson 2012).

347 However, a common pattern for both lake types was that taxon richness decreased from the slow

348 group towards the intermediate and faster group, whilst the group of stochastic species had highest

349 richness in both lake types (Fig. 3A). A similar pattern was found for acid-sensitive taxa, although

350 circum-neutral lakes had a higher richness of these taxa across the different temporal patterns

351 identified relative to the acidified lakes (Fig. 3B). Despite these structural differences between

352 acidified and circum-neutral lakes, functional richness, functional diversity and functional evenness

353 showed similar ranges across species groups and lake types (Fig. 3C-E).

354 Coincident with patterns of taxon richness, average functional redundancy was also highest in

355 the stochastic species group, followed by the slow frequency group in acidified and circum-neutral

356 lakes (Fig. 3F). Both circum-neutral and acidified lakes showed similar variability in cross-scale

357 redundancy (Fig. 3G). The importance of stochastic species was also reflected in ANOVA analyses.

358 Higher values for many metrics were found for stochastic species relative to the slow, intermediate

359 and fast groups of species (Tukey HSD test: $\mathrm{P}<0.05$ ) leading to a highly significant "temporal

360 pattern” term in the model (Table 1). A significant “lake type” effect was found for richness of acid

361 sensitive taxa and average functional redundancy; overall species richness was marginally $(p=0.07)$

362 higher in circum-neutral lakes (Table 1). However, none of the interaction terms between lake type

363 and temporal patterns was significant, highlighting that the distributions of functions necessary for

364 understanding the relative resilience of ecosystems was similar between the acidified and circum-

365 neutral lakes.

366 Predators and gatherers were the dominant feeding types, with the highest level of functional

367 redundancy in the slow, intermediate, fast and stochastic species groups in both lake types, relative to 
368 the other feeding groups (Fig. 4). The average redundancy for predators and gatherers was higher

369 than for other feeding groups in all frequency fluctuation groups identified (Tukey HSD test:

370 Predators $=$ Gatherers $>$ Grazers $=$ Shredders $=$ Filterers $=$ Omnivores $)($ Table 1$)$. Circum-neutral

371 lakes had a significantly higher within-scale redundancy in the slow and stochastic species group

372 relative to acidified lakes (Table 1); however, interactions between lake type and functional feeding

373 group were non-significant for within-scale redundancy, highlighting similarities between both lake

374 types (Table 1). Also, the patterns of cross-scale redundancy for each functional feeding group were

375 similar for both lake types (Fig. 4), resulting in non-significant effects in the ANOVAs (Table 1).

376 The complementary multivariate analyses are in agreement with the patterns found for

377 univariate metrics. Stochastic groups of acidified and circum-neutral lakes with highest richness and

378 functional redundancy clustered towards the right side in multivariate (NMDS) ordination space. The

379 slow species groups in both lake types clustered close to the stochastic species, while the

380 intermediate and faster groups moved towards the left in ordination space, reflecting decreasing

381 species richness and functional redundancy (Fig. 5). Similar to the univariate ANOVA,

382 PERMANOVA based on Bray-Curtis similarities (emphasizing both taxa presences-absences and

383 their abundances) and Sorensen similarity (focusing only on presence-absences) revealed a

384 significant "pattern effect". This highlights the difference of the stochastic species group from the

385 slow, intermediate and fast frequency fluctuation groups. However, the non-significant interaction

386 term in both models highlights similar distribution of functions between lake types and temporal

387 patterns (Table 2).

\section{Discussion}

390 We tested the proposition that acidified lakes are more vulnerable to environmental change, raising

391 concerns about potential regime shifts in the future, relative to circum-neutral lakes. The low $\mathrm{pH}$

392 values throughout our study $(<6)$ and the lower number of acid-sensitive taxa in acidified lakes 
393 suggest weak chemical and biological recovery. Thus, the acidified lakes studied here remain

394 degraded, despite the implementation of acidification mitigation policy decades ago. Poor habitat

395 quality (Kowalik et al. 2007), combined with altered local (biological structure and food webs; e.g.

396 Ledger and Hildrew 2005) and regional factors (limited dispersal and population connectivity; Gray

397 and Arnott 2011) have been considered major factors maintaining acidified systems in degraded

398 conditions.

399 Although signs of recovery of acidified lakes were weak, we observed broader environmental

400 change responses that were manifest in similar temporal patterns of environmental variables in both

401 lake types. Consistent with observations made in streams, lakes and ponds across Europe (Evans et

402 al. 2005; Van Kleef et al. 2010), acidified and circum-neutral lakes have experienced a gradual

403 change in water clarity (decreased Secchi disk transparency, increasing TOC concentrations and

404 water colour), which has been attributed to decreasing acid deposition, global warming and land-use

405 change (Evans et al. 2005; Monteith et al. 2007). Concomitant with changes in the abiotic

406 environment, other studies have reported biotic changes, including the range expansions of invasive,

407 nuisance species (Angeler et al. 2012; Trigal et al. 2013) or altered local and regional community

408 structure in lakes (Burgmer et al. 2007). Collectively, these changes show that boreal lakes are

409 affected by environmental change that goes beyond the acidification problem, and similar changes

410 have been observed elsewhere (e.g. Batterbee et al. 2014).

411 It is uncertain whether the complex ecological changes that affect acidified and circum-

412 neutral lakes similarly will eventually increase the risk of regime shifts in the future. One way to

413 cope with this uncertainty is to assess the vulnerability of lakes to further environmental change by

414 quantifying the attributes of ecological resilience. Many studies have assessed community structure

415 and composition in lakes recovering from acidification (e.g. Hogsden and Vinebrooke 2005, Wesolek

416 et al. 2010). Our study, based on a quantitative assessment of resilience, is the first attempt to test

417 whether acidified lakes in a degraded state are potentially more vulnerable to environmental change 
than circum-neutral lakes in desirable states.

419 We expected that acidified lakes would exhibit higher vulnerability to environmental change

420 than circum-neutral lakes. We assessed resilience following the cross-scale resilience model

421 (Peterson et al. 1998) and quantified within-scale and cross-scale redundancy. We also quantified

422 additional functional measures (functional richness, functional diversity, functional evenness) for the

423 temporal patterns identified by the time series modeling to allow for a broader characterization of

424 resilience (Angeler et al. 2013a). If acidified lakes are less resilient and thus more vulnerable to

425 environmental change, these measures should be reflected in lower values in acidified relative to

426 circum-neutral lakes. However, comparing the distributions of functional metrics within and across

427 temporal scales and within species groups showing stochastic dynamics, both critical components for

428 quantifying the relative resilience in ecosystems (Peterson et al. 1998; Allen et al. 2005; Baho et al.

429 2014), failed to discern a relationship between lake type (i.e. acidified vs circum-neutral lakes) and

430 temporal pattern in either the univariate or multivariate analyses. Overall, this suggests that

431 invertebrates in acidified and circum-neutral lakes have similar functional attributes that characterize

432 their relative resilience through time. This finding was unexpected because invertebrate communities

433 in the acidified and circum-neutral systems differ both in terms of community composition and

434 trophic associations in their food webs (Ledger and Hildrew 2005; Angeler and Goedkoop 2010;

435 Baho et al. 2014). Our results suggest that despite inherent abiotic and biotic differences between

436 acidified and circum-neutral lakes, the functional attributes in all species groups associated with

437 different temporal patterns were similar. This suggests that resilience in both lakes types is similar,

438 and in turn that acidified and circum-neutral lakes are similarly vulnerable to the environmental

439 change observed in this study. Similar patterns have been found comparing subarctic lakes with a

440 presumed high vulnerability to climate change and hemiboreal lakes at more southern latitudes

441 (Angeler et al. 2013a), and degraded avian communities on continental prairies (Sundstrom et al.

442 2012). Further studies that quantify attributes of resilience are warranted to test for the generalities of 
443 patterns observed in this study and the subarctic lakes and prairies studies.

444 It is often assumed that impacts of environmental change on biodiversity lead to a decreased

445 resilience in ecosystems (Peterson et al. 1998; Folke et al. 2004; Fischer et al. 2006). Our results

446 suggest that such an assumption is too simplistic, and that accounting for scale-specific drivers of

447 environmental change divers and compensational processes may explain the underlying mechanisms.

448 The impacts of environmental change are scale-specific (Nash et al. 2014). We found variables

449 related to environmental change (acidity, water color) correlating only with specific species groups

450 revealed by the time series modeling. The temporal patterns of other species groups were largely

451 uncorrelated with these variables, and likely associated with other unmeasured abiotic and biotic

452 variables, including dispersal. This resistance at specific scales may help to buffer impacts of

453 environmental change at other scales and confer resilience to ecosystems (Angeler et al. 2013a).

454 We found that richness of acid-sensitive taxa was lower in the acidified lakes relative to the

455 circum-neutral lakes in this study. Overall taxon richness was only marginally higher in circum-

456 neutral lakes (Table 1). This suggests that other species, tolerant to acidification stress have likely

457 substituted acid-sensitive taxa (Layer et al. 2010). More importantly, these tolerant species seemed to

458 have compensated for the loss of functional attributes of these sensitive taxa. This in turn can explain

459 the similar resilience characteristics observed in acidified and circum-neutral lakes. This finding

460 supports the notion that both degraded and undegraded states of ecosystems can be equally resilient

461 (Standish et al. 2014). Similar functional compensation processes have been observed in some

462 studies (Klug et al. 2000; Fischer et al. 2001). However, other studies have reported week

463 compensatory processes (Huijbers et al. 2015) or that these processes vary depending on context

464 (Yang et al. 2014). This context dependency adds uncertainty to environmental change outcomes,

465 further underscoring the need for more systemic approaches to assess vulnerability to environmental

466 change. Although our study showed similar patterns of vulnerability of acidified and circum-neutral

467 lakes to the environmental change observed in this study, further research comparing different 
468 ecosystem types along a range of stress gradients is required to further understand the role of 469 compensatory dynamics in environmental change outcomes.

Despite both lake types sharing similar resilience characteristics, we found scale-inherent

471 patterns and different contributions of functional feeding groups that must be considered for

472 understanding the overall resilience of the studied lakes. Johnson et al. (2004) found that filterers had

473 the lowest and predators and gatherers the highest representation in the invertebrate communities.

474 Consistent with these findings, filterers, shredders, grazers and omnivores had the lowest, and 475 gatherers and predators the highest within-scale redundancy in this study. Similar patterns were 476 found for cross-scale redundancy, and the stochastic group of species considered important for 477 mediating the adaptive capacity of these functional feeding groups. The loss of functional group 478 representation at one or more scales, and reduced adaptive capacity resulting from species with 479 stochastic dynamics, would have a larger impact on resilience than the loss of species from 480 functional groups with high redundancy. Our results show that filterers and shredders are the 481 functional groups most vulnerable to loss from lakes. While this suggests that these groups should be 482 most carefully monitored, we recognize that these groups usually are much more abundant in streams 483 (Johnson et al. 2004) and that their contribution to matter flux in lakes is low (Bohman and Tranvik 484 2001). Gatherers and predators had the highest redundancy across lakes and the loss of one or a few 485 species from these functional groups would have relatively minor impact on resilience.

486 We acknowledge that we have characterized resilience based on functional feeding group

487 attributes, which are relatively coarse measures of functional traits. Our analysis is restricted to 488 autumn samples of invertebrates. It is possible that increasing the temporal resolution to also cover 489 seasonal dynamics would have refined our results. Our classification of functional traits is also 490 limited by our current limited knowledge of the ecology and natural history of most species.

491 Resilience assessments might be refined by considering multiple traits within individual species that 492 characterize response diversity (Elmqvist et al. 2003) or through a direct measurement of process 
493 rates. We were unable to consider response diversity or processes in our study because of currently

494 insufficient trait information and because our monitoring program does not quantify process rates.

495 Also, a comparison of resilience attributes across multiple taxonomic groups would allow for a more

496 accurate definition of the broader vulnerability of lakes to environmental change. Despite these

497 limitations, our study shows how long-term monitoring efforts, combined with an ecological

498 complexity approach that is often neglected in assessing environmental change problems, can

499 facilitate an evaluation of systemic vulnerability to changing environmental conditions. Measuring

500 ecological resilience attributes, and comparing these attributes across system types with presumed

501 different vulnerabilities has potential to identify ecosystems at risk of undergoing catastrophic regime

502 shifts. This can contribute to reduce uncertainty in the assessment of the potential sensitivity of

503 ecosystems to environmental change, and facilitate the planning of management and conservation

504 action in the long term.

505

506 Acknowledgements

507 Funding was provided by the Swedish Environmental Protection Agency (Dnr 10/179), the Swedish

508 Agency for Marine and Water Management (HaV), the Lakes and Watercourses Monitoring Program

509 (FOMA-SLU), the August T. Larsson Foundation (NJ Faculty, SLU), and grants from the Swedish

510 research councils Vetenskapsrådet (2014-5828) and Formas (2014-1193). The Nebraska

511 Cooperative Fish and Wildlife Research Unit is jointly supported by a cooperative agreement

512 between the U.S. Geological Survey, the Nebraska Game and Parks Commission, the University of

513 Nebraska-Lincoln, the U.S. Fish and Wildlife Service and the Wildlife Management Institute. Any

514 use of trade, firm, or product names is for descriptive purposes only and does not imply endorsement

515 by the U.S. Government. We thank the reviewers, Frauke Ecke and C.H. Peterson for constructive

516 feedback that helped improve the paper. 


\section{$517 \quad$ Literature cited}

518 Allen CR, Angeler DG, Garmestani AS, Gunderson LH, Holling CS (2014) Panarchy: Theory and $519 \quad$ application. Ecosystems 17:578-589

520 Allen CR, Gunderson L, Johnson AR (2005) The use of discontinuities and functional groups to 521 assess relative resilience in complex systems. Ecosystems 8:958-966

522 Anderson MJ (2005) PERMANOVA: a FORTRAN computer program for permutational 523 multivariate analysis of variance. Department of Statistics, University of Auckland, New $524 \quad$ Zealand.

525 Angeler DG, Viedma O, Moreno JM (2009) Statistical performance and information content of time 526 lag analysis and redundancy analysis in time series modeling. Ecology 90:3245-3257

527 Angeler DG, Goedkoop W (2010) Biological responses to liming in boreal lakes: an assessment 528 using plankton, macroinvertebrate and fish communities. J Appl Ecol 47:478-486

529 Angeler DG, Drakare S, Johnson RK (2011) Revealing the organization of complex adaptive systems 530 using multivariate time series modeling. Ecol Soc 16:5. http://dx.doi.org/10.5751/ES-04175-

$531 \quad 160305$

532 Angeler DG, Johnson RK (2012) Temporal scales and patterns of invertebrate biodiversity dynamics 533 in boreal lakes recovering from acidification. Ecol Appl 22:1172-1186

534 Angeler DG, Allen CR, Johnson RK (2012) Insight on invasions and resilience derived from

535 spatiotemporal discontinuities of biomass at local and regional scales. Ecol Soc 17(2):32 536 http://www.ecologyandsociety.org/vol17/iss2/art32/

537 Angeler DG, Allen CR, Johnson RK (2013a) Measuring the relative resilience of subarctic lakes to 538 global change: redundancies of functions within and across temporal scales. J Appl Ecol $539 \quad 50: 572-584$

540 Angeler DG, Allen CR, Rojo C, Alvarez-Cobelas M, Rodrigo MA, Sánchez-Carrillo S (2013b) 
Inferring the relative resilience of alternative states. PLoS ONE 8(10):e77338 doi:10.1371/journal.pone.0077338

543 Angeler DG, Allen CR, Birgé HE, Drakare S, McKie BG, Johnson RK (2014) Assessing and

544 managing freshwater ecosystems vulnerable to environmental change. AMBIO 43:113-125

545 Baho DL, Drakare S, Johnson RK, Allen CR, Angeler DG (2014) Similar resilience characteristics

546 in lakes with different management practices. PLOS ONE 9(3): e91881.

547 doi:10.1371/journal.pone.0091881

548 Barnosky AD, Hadly EA, Bascompte J et al. (2012) Approaching a state shift in Earth’s biosphere.

$549 \quad$ Nature 486:52-58

550 Batterbee RW, Shilland EM, Kernan M, Monteith DT, Curtis CJ (2014) Recovery of acidified

551 surface waters from acidification in the United Kingdom after twenty years of chemical and

552 biological monitoring (1988-2008). Ecol Ind 37(Part B):267-273

553 Blanchet FG, Legendre P, Borcard D (2008) Modeling directional spatial processes in ecological

554 data. Ecol Model 215:325-336

555 Bohman I, Tranvik L (2001) The effects of shredding invertebrates on the transfer of organic carbon

556 from littoral leaf litter to water-column bacteria. Aquat Ecol 35:43-50

557 Burgmer T, Hillebrand H, and Pfenninger M (2007) Effects of climate-driven temperature changes

558 on the diversity of freshwater macroinvertebrates. Oecologia 151:93-103

559 Burns DA, Riva-Murray K, Bode RW, Passy S (2008) Changes in stream chemistry and biology in

560 response to reduced levels of acid deposition during 1987-2003 in the Neversink River

$561 \quad$ Basin, Catskill Mountains. Ecol Ind 8:191-203

562 Carpenter S, Walker B, Anderies JM, Abel N (2001) From metaphor to measurement: resilience of

563 what to what? Ecosystems 4:765-781

564 Covich AP, Palmer MA, Cowl TA (1999) The role of benthic invertebrate species in freshwater

565 ecosystems: Zoobenthic species influence energy flows and nutrient cycling. BioScience 
567 Elmqvist T, Folke C, Nyström M, Peterson G, Bengtsson J, Walker B, Norberg J (2003) Response

568 diversity, ecosystem change and resilience. Front Ecol Environ 1:488-494

569 Evans CD, Monteith DT, Cooper DM (2005) Long-term increases in surface water dissolved organic

570 carbon: observations, possible causes and environmental impacts. Environ Poll 137:55-71

571 Fischer J, Lindenmayer DB, Manning AD (2006) Biodiversity, ecosystem function, and

572 resilience: ten guiding principles for commodity production landscapes. Front Ecol

$573 \quad$ Environ 4:80-86

574 Fischer J, Lindenmeyer DB, Blomberg SP, Montague-Drake R, Felton A, Stein JA (2007) Functional

575 richness and relative resilience of bird communities in regions with different land use

$576 \quad$ intensities. Ecosystems 10:964-974

577 Fischer JM, Frost TM, Ives AR (2001) Compensatory dynamics in zooplankton community

578 responses to acidification: measurement and mechanisms. Ecol Appl 11:1060-1072

579 Folke C, Carpenter S, Walker B, Scheffer M, Elmqvist T, Gunderson LH, Holling CS (2004) Regime

580 shifts, resilience, and biodiversity in ecosystem management. Annu Rev Ecol Evol Syst

$581 \quad 35: 557-581$

582 Fölster J, Andrén C, Bishop K, et al (2007) A novel environmental quality criterion for acidification

583 in Swedish lakes - an application of studies on the relationship between biota and water

$584 \quad$ chemistry. Wat Air Soil Poll: Focus 7:331-338

585 Fölster J, Johnson RK, Futter MN, Wilander A (2014) The Swedish monitoring of surface waters: 50

$586 \quad$ years of adaptive monitoring. AMBIO 43:3-18

587 Gray DK, Arnott SE (2011) Does dispersal limitation impact the recovery of zooplankton communities damaged by a regional stressor? Ecol Appl 21:1241-1256

589 Hirota M, Holmgren M, Van Nes E, Scheffer M (2011) Global resilience of tropical forest and 
savanna to critical transitions. Science 334:232-235

591 Hogsden KL, Vinebrooke RD (2005) Environmental predictors of benthic consumers and autotrophic 592 communities along a recovery gradient. Can J Fish Aquat Sci 62:2226-2239

593 Holling CS (1973) Resilience and stability of ecological systems. Ann Rev Ecol Syst 4:1-23

594 Hooper DU et al (2005) Effects of biodiversity on ecosystem functioning: a consensus of current

$595 \quad$ knowledge. Ecol Monogr 75:3-35

596 Hughes TP, Carpenter S, Rockström J, Scheffer M, Walker B (2013) Multiscale regime shifts and 597 planetary boundaries. Trends Ecol Evol 28:389-395

598 Huijbers CM, Schlacher TA, Schoeman DS, Olds AD, Weston MA, Connolly RM (2015) Limited 599 functional redundancy in vertebrate scavenger guilds fails to compensate for the loss of 600 raptors from urbanized sandy beaches. Divers Distrib 21:55-63

601 Johnson RK (1999) Regional representativeness of Swedish reference lakes. Env Manage 23:115$602 \quad 124$

603 Johnson RK, Angeler DG (2010) Tracing recovery under changing climate: response of 604 phytoplankton and invertebrate assemblages to decreased acidification. J N Am Benthol Soc $605 \quad 29: 1472-1490$

606 Johnson RK, Goedkoop W, Sandin L (2004) Spatial scale and ecological relationships between the 607 macroinvertebrate communities of stony habitats of streams and lakes. Freshwat Biol $608 \quad 49: 1179-1194$

609 Jost L (2007) Partitioning diversity into independent alpha and beta components. Ecology 88:2427$610 \quad 2439$

611 Klug JL, Fischer JM, Ives AR, Dennis B (2000) Compensatory dynamics in planktonic community 612 responses to $\mathrm{pH}$ perturbations. Ecology 81:387-398

613 Kosten S, Vernooij M, Van Nes EH, Sagrario MDLG, Clevers JGPW, Scheffer M (2012) Bimodal 614 transparency as an indicator for alternative states in South American lakes. Freshwat Biol 
616 Kowalik RA, Cooper DM, Evans CD, Ormerod SJ (2007) Acidic episodes retard the biological 617 recovery of upland British streams from chronic acidification. Glob Change Biol 13:2439$618 \quad 2452$

619 Layer K, Hildrew A, Monteith D, Woodward G (2010) Long-term variation in the littoral food web 620 of an acidified mountain lake. Glob Change Biol 16:3133-3143

621 Ledger ME, Hildrew AG (2005) The ecology of acidification and recovery: changes in herbivore622 algal food web linkages across a stream pH gradient. Env Poll 137:103-118

623 Monteith DT, Stoddard JL, Evans CD, et al. (2007) Dissolved organic carbon trends resulting from 624 changes in atmospheric deposition chemistry. Nature 450:537-541

625 Nash KL, Allen CR, Angeler DG, et al. (2014) Discontinuities, cross-scale patterns and the 626 organization of ecosystems. Ecology 95:654-667

627 Ormerod SJ, Durance I (2009) Restoration and recovery from acidification in upland Welsh streams 628 over 25 years. J Appl Ecol 46:164-174

629 Peterson GD, Allen CR, Holling CS (1998) Ecological resilience, biodiversity, and scale. Ecosystems $630 \quad 1: 6-18$

631 Pimm SL (1991) The Balance of Nature? Univ Chicago Press, Chicago.

632 R Development Core Team (2012) R: A language and environment for statistical computing. R 633 Foundation for Statistical Computing, Vienna, Austria.

634 Scheffer M, Carpenter S (2003) Catastrophic regime shifts in ecosystems: linking theory to 635 observation. Trends Ecol Evol 18:648-656

636 Schindler DW (1988) Effects of acid rain on freshwater ecosystems. Science 239:149-157

637 Skjelkvåle BL, Evans CD, Larssen T, Hindar A, Raddum G (2003) Recovery from acidification in 638 European surface waters: a view to the future. Ambio 32:170-175

639 Schmidt-Kloiber A, Hering D (2012) www.freshwaterecology.info - the taxa and autecology 
database for freshwater organisms, version 5.0.

641 Stoddard JL, et al (1999) Regional trends in aquatic recovery from acidification in North America 642 and Europe. Nature 401:575-578

643 Stow C, Allen CR, Garmestani AS (2007) Evaluating discontinuities in complex systems: toward 644 quantitative measures of resilience. Ecol Soc 12:26

645 http://www.ecologyandsociety.org/voll2/issl/art26/

646 Sundstrom SM, Allen CR, Barichievy C (2012) Species, functional groups, and thresholds in 647 ecological resilience. Cons Biol 26:305-314

648 Standish RJ, Hobbs RJ, Mayfield MM, Bestelmeyer BT, Suding KN, Battaglia LL, Eviner V, 649 Hawkes CV, Temperton VM, Vramer BA, Harris JA, Funk JL, Thomas PA (2014) Resilience 650 in ecology: Abstraction, distraction, or where the action is? Biol Cons 177:43-51

651 Trigal C, Hallstan S, Johansson KS, Johnson RK (2013) Factors affecting occurrence and bloom 652 formation of the nuisance flagellate Gonyostomum semen in boreal lakes. Harmful Algae $653 \quad 27: 60-67$

654 Tuomisto H (2010) A diversity of beta diversities: straightening up a concept gone awry. Part 1.

655 Defining beta diversity as a function of alpha and gamma diversity. Ecography 33:2-22

656 Tuomisto H (2012) An updated consumerÅLs guide to evenness and related indices. Oikos

$657 \quad 121: 1203-1218$

658 Van Kleef HH, Brouwer E, Leuven RSEW, van Dam H, de Vires-Brock A, van der Velde G, 659 Esselink H (2010) Effects of reduced nitrogen and sulphur deposition on the water chemistry 660 of moorland pools. Env Poll 158:2679-2685

661 Walker B, Kinzig A, Langridge J (1999) Plant attribute diversity, resilience, and ecosystem function:

662 The nature and significance of dominant and minor species. Ecosystems 2:95-113

663 Walker B, Holling CS, Carpenter, SR, Kinzig A (2004) Resilience, adaptability and 
transformability in social-ecological systems. Ecol Soc 9(2):5

665 Wesolek BE, Genrich EK, Gunn JM, Somers KM (2010) Use of littoral benthic invertebrates to 666 assess factors affecting biological recovery of acid- and metal-damaged lakes. J N Am 667 Benthol Soc 29:572-585

668 Yan ND, Keller W, Somers KM, Pawson TW, Girard RE (1996) Recovery of crustacean zooplankton 669 from acid and metal contamination: comparing manipulated and reference lakes. Can J Fish $670 \quad$ Aquat Sci 53:1301-1327

671 Yang G, Liu N, Lu W, Wang S, Kan H, Zhang Y, Xu L, Chen Y (2014) The interaction between 672 arbuscular mycorrhizal fungi and soil phosphorus availability influences plant community 673 productivity and ecosystem stability. J Ecol 102:1072-1082

674

675

676

677 Electronic Supplementary Material

678 1. Flow chart outlining steps to time series modeling.

679 2. Table of water quality characteristics and geographical coordinates of acidified and circum-neutral 680 lakes.

681 3. Results from Spearman rank correlation analyses.

682 
Table 1: Results from ANOVA analyses contrasting effects of lake type (circum-neutral vs acidified lakes) and temporal pattern (“slow” vs "intermediate” vs "faster” vs "stochastic" species group) (a) and lake type and feeding groups (predators, shredders, gatherers, grazers, filterers, omnivores) (b), and their interactions, on measures used to assess the relative resilience of lakes. Shown are degrees of freedom (df), mean squares, sources of variation (F ratios), significance levels and error terms. Significant effects are highlighted in bold.

\begin{tabular}{|c|c|c|c|c|c|c|c|c|c|c|}
\hline \multirow[t]{2}{*}{ a) } & \multicolumn{3}{|c|}{$\begin{array}{l}\text { Lake type (LT) } \\
\text { df }(1,40)\end{array}$} & \multicolumn{3}{|c|}{$\begin{array}{l}\text { Pattern (P) } \\
\text { df }(3,40)\end{array}$} & \multicolumn{3}{|l|}{$\begin{array}{l}\text { L x P df } \\
(3,40)\end{array}$} & \multirow[t]{2}{*}{ Error } \\
\hline & MS & $\mathrm{F}$ & $\mathrm{P}$ & MS & $\mathrm{F}$ & $\mathrm{P}$ & MS & $\mathrm{F}$ & $\mathrm{P}$ & \\
\hline Taxon richness & 0.14 & 3.35 & 0.07 & 2.71 & 67.03 & $<0.001$ & 0.01 & 0.12 & 0.95 & 0.04 \\
\hline $\begin{array}{l}\text { Richness acid- } \\
\text { sensitive taxa }\end{array}$ & 1.11 & 17.52 & $<0.001$ & 1.60 & 25.32 & $<0.001$ & 0.02 & 0.32 & 0.81 & 0.06 \\
\hline $\begin{array}{l}\text { Functional } \\
\text { richness }\end{array}$ & 0.01 & 1.12 & 0.30 & 0.04 & 3.44 & 0.03 & 0.01 & 0.94 & 0.43 & 0.01 \\
\hline $\begin{array}{l}\text { Functional } \\
\text { diversity }\end{array}$ & 0.02 & 1.92 & 0.17 & 0.02 & 3.08 & 0.03 & $<0.001$ & 0.02 & 0.89 & 0.01 \\
\hline $\begin{array}{l}\text { Functional } \\
\text { evenness }\end{array}$ & $<0.001$ & 0.76 & 0.38 & 1.65 & 104.79 & $<0.001$ & 0.001 & 3.19 & 0.034 & $<0.001$ \\
\hline $\begin{array}{l}\text { Average within- } \\
\text { scale redundancy }\end{array}$ & 0.09 & 5.53 & 0.02 & 0.22 & 8.95 & $<0.001$ & 0.01 & 0.56 & 0.64 & 0.02 \\
\hline \multirow[t]{2}{*}{ b) } & \multicolumn{3}{|c|}{$\begin{array}{l}\text { Lake type (LT) } \\
\text { (df } 1,60)\end{array}$} & \multicolumn{3}{|c|}{$\begin{array}{l}\text { Feeding group (F) } \\
(\mathrm{df} 5,60)\end{array}$} & \multicolumn{3}{|c|}{$\begin{array}{l}\text { LT x F } \\
(\text { df } 5,60)\end{array}$} & Error \\
\hline & MS & $\mathrm{F}$ & $\mathrm{P}$ & MS & $\mathrm{F}$ & $\mathrm{P}$ & MS & $\mathrm{F}$ & $\mathrm{P}$ & \\
\hline $\begin{array}{l}\text { Within-scale } \\
\text { redundancy } \\
\text { (Temporal scale 1) }\end{array}$ & 0.45 & 10.68 & 0.002 & 1.22 & 28.85 & $<0.001$ & 0.03 & 0.66 & 0.66 & 0.042 \\
\hline $\begin{array}{l}\text { Within-scale } \\
\text { redundancy } \\
\text { (Temporal scale 2) }\end{array}$ & $<0.001$ & 0.001 & 0.978 & 0.51 & 10.58 & $<0.001$ & 0.10 & 1.97 & 0.10 & 0.048 \\
\hline $\begin{array}{l}\text { Within-scale } \\
\text { redundancy } \\
\text { (Temporal scale 3) }\end{array}$ & 0.02 & 0.59 & 0.336 & 0.44 & 11.32 & $<0.001$ & 0.03 & 0.83 & 0.53 & 0.039 \\
\hline $\begin{array}{l}\text { Within-scale } \\
\text { redundancy } \\
\text { (Stochastic) }\end{array}$ & 0.67 & 18.86 & $<0.001$ & 1.95 & 55.01 & $<0.001$ & 0.07 & 1.85 & 0.12 & 0.036 \\
\hline $\begin{array}{l}\text { Cross-scale } \\
\text { redundancy }\end{array}$ & 0.03 & 1.49 & 0.23 & 0.17 & 9.57 & $<0.001$ & 0.01 & 0.50 & 0.78 & 0.018 \\
\hline
\end{tabular}


Table 2: Results of PERMANOVA analysis contrasting multivariate community structure based on Bray-Curtis and Sørensen similarity between lake type (circum-neutral vs acidified lakes), temporal pattern ("slow" vs "intermediate" vs "fast" vs "stochastic" species groups) and their interactions. Shown are degrees of freedom (df), sums of squares (SS), mean squares (MS), Fratios (F), and the Monte Carlo asymptotic P values (P(MC)). Significant effects are highlighted in bold.

\begin{tabular}{llllll}
\hline Source & df & SS & MS & F & P (MC) \\
\hline Bray-Curtis & & & & & \\
$\quad$ Lake type & 1 & 838.59 & 838.59 & 1.50 & 0.202 \\
Pattern & $\mathbf{3}$ & $\mathbf{2 5 0 2 8 . 3 3}$ & $\mathbf{8 3 4 2 . 7 8}$ & $\mathbf{1 4 . 9 2}$ & $<\mathbf{0 . 0 0 1}$ \\
Lake type x pattern & 3 & 2137.51 & 712.50 & 1.27 & 0.261 \\
$\quad$ Residual & 40 & 22370.63 & 559.27 & & \\
$\quad$ Total & 47 & 50375.06 & & & \\
Sørensen & & & & & \\
$\quad$ Lake type & 1 & 523.48 & 523.48 & 1.35 & 0.294 \\
$\quad$ Pattern & $\mathbf{3}$ & $\mathbf{4 3 9 8 . 7 6}$ & $\mathbf{1 4 6 6 . 2 5}$ & $\mathbf{3 . 7 8}$ & $\mathbf{0 . 0 0 4}$ \\
Lake type x pattern & 3 & 1528.99 & 509.66 & 1.31 & 0.286 \\
$\quad$ Residual & 40 & 15532.28 & 388.31 & & \\
Total & 47 & 21983.51 & & & \\
\hline
\end{tabular}




\section{Figure legends}

Fig. 1 Temporal patterns of environmental variables in circum-neutral $(\mathrm{N}=6)$ and acidified $(\mathrm{N}=6)$ lakes. Shown are the means \pm standard deviations of circum-neutral (black lines) and acidified (grey lines) lakes. The trend lines indicate significant monotonic change over time revealed by Kendall tau correlation analyses

Fig. 2 Temporal patterns of species groups associated with canonical axes obtained from multivariate time series modeling of invertebrate communities in circum-neutral (2A-F) and acidified (2G-L) lakes. Shown are linear combination scores of significant AEM variables (see methods for details)

Fig. 3 Comparison of structural (total taxon richness, 3A; richness acid-sensitive taxa, 3B), functional (3C-E) community metrics, and average within-scale redundancy (3F) associated with the temporal patterns identified by time series modeling for acidified (grey bars) and circumneutral (black bars) lakes. Shown is also the average cross-scale redundancy for acidified and circum-neutral lakes (3G). Shown are means \pm standard deviations of acidified $(\mathrm{N}=6)$ and circum-neutral $(\mathrm{N}=6)$ lakes

Fig. 4 Patterns of within-scale redundancy associated with temporal patterns identified by time series modeling for predators (4A), gatherers (4B), grazers (4C), omnivores (4D), shredders (4E) and filterers (4F) for acidified (grey bars) and circum-neutral lakes (black bars). Shown are also the cross-scale redundancies for each feeding group in both lake types (4G-L)

Fig. 5 Nonmetric multidimensional scaling ordination (Bray-Curtis based) showing similarities of functional attributes across species groups with slow (squares), intermediate (circles), faster (diamonds) species groups in acidified (white symbols) and circum-neutral (black symbols) lakes. For lakes Humsjön and Harasjön functional attributes associated with a fourth temporal 
pattern (triangles) are shown. Also shown are, similarities of functional characteristics of groups of species with stochastic dynamics (grey symbols) 
Fig. 1
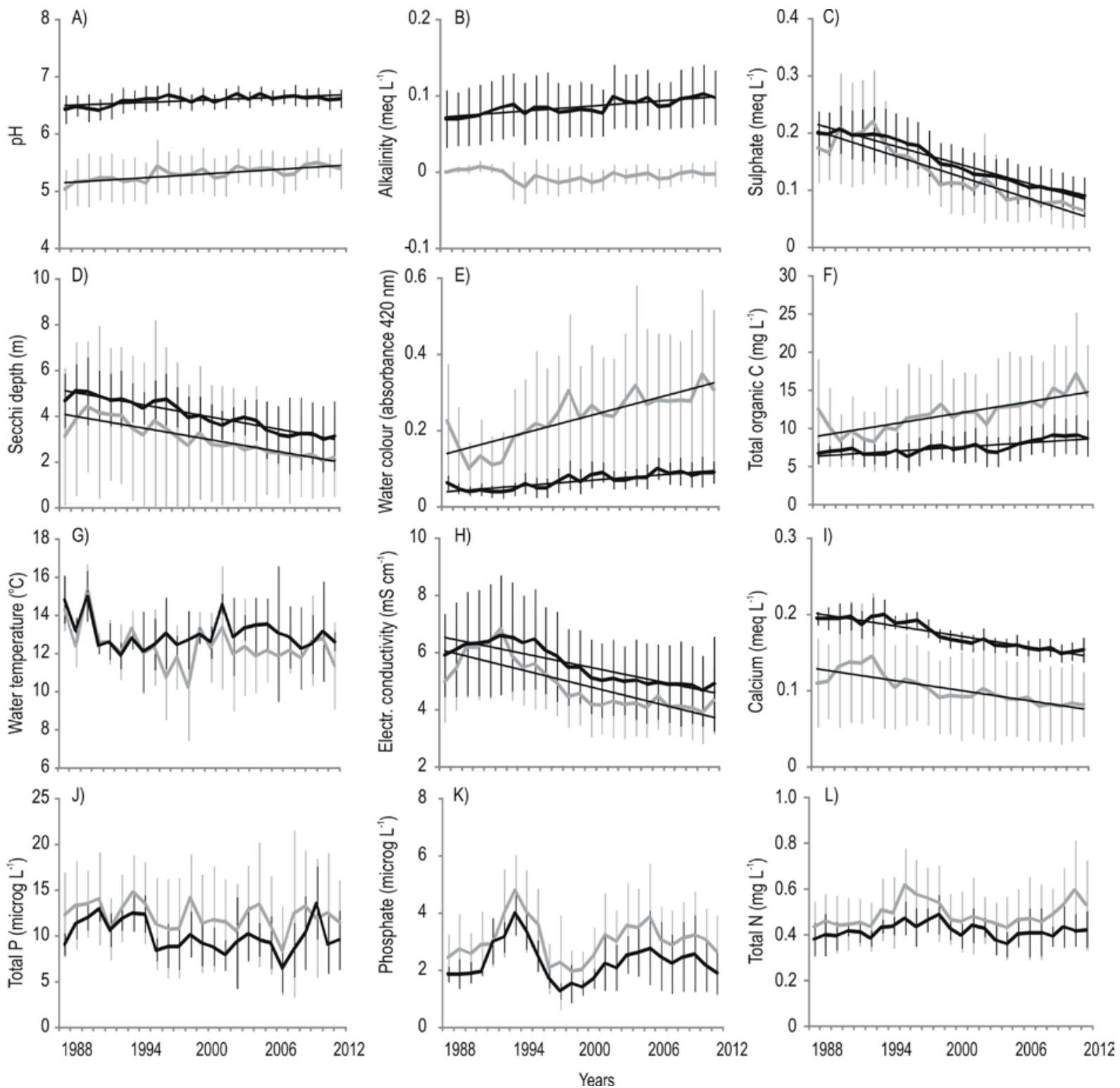
Fig. 2

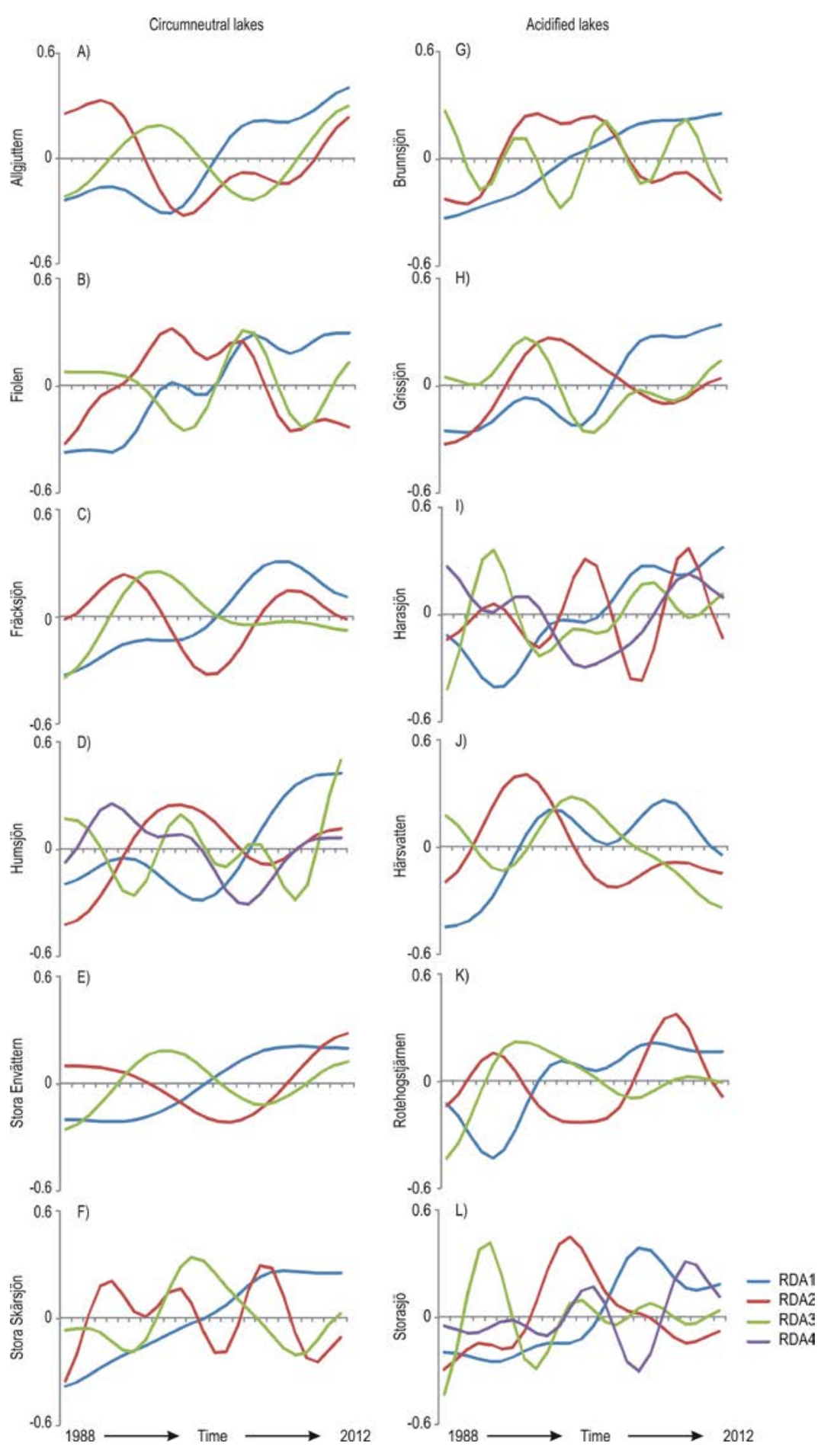


Fig. 3
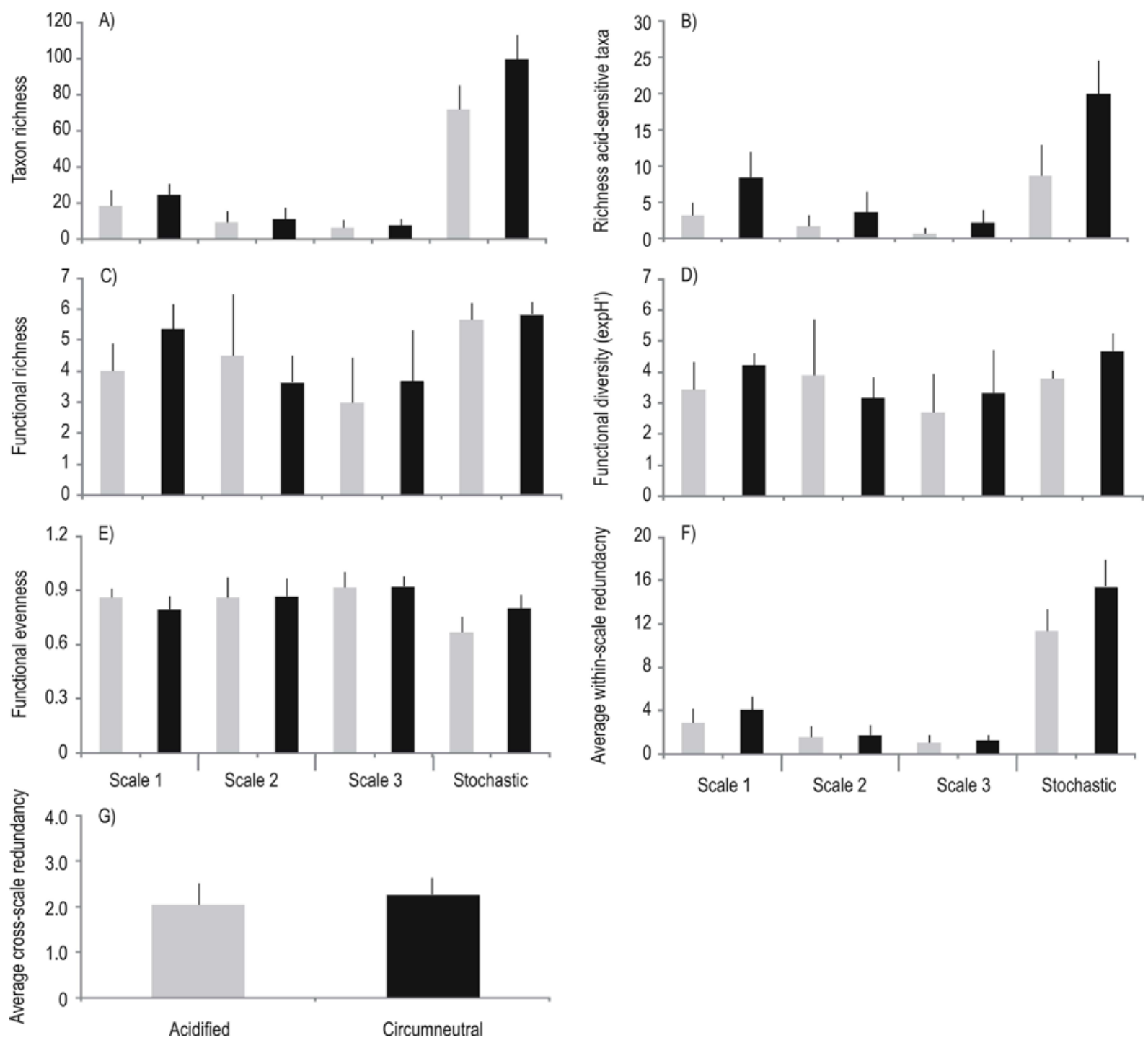
Fig. 4

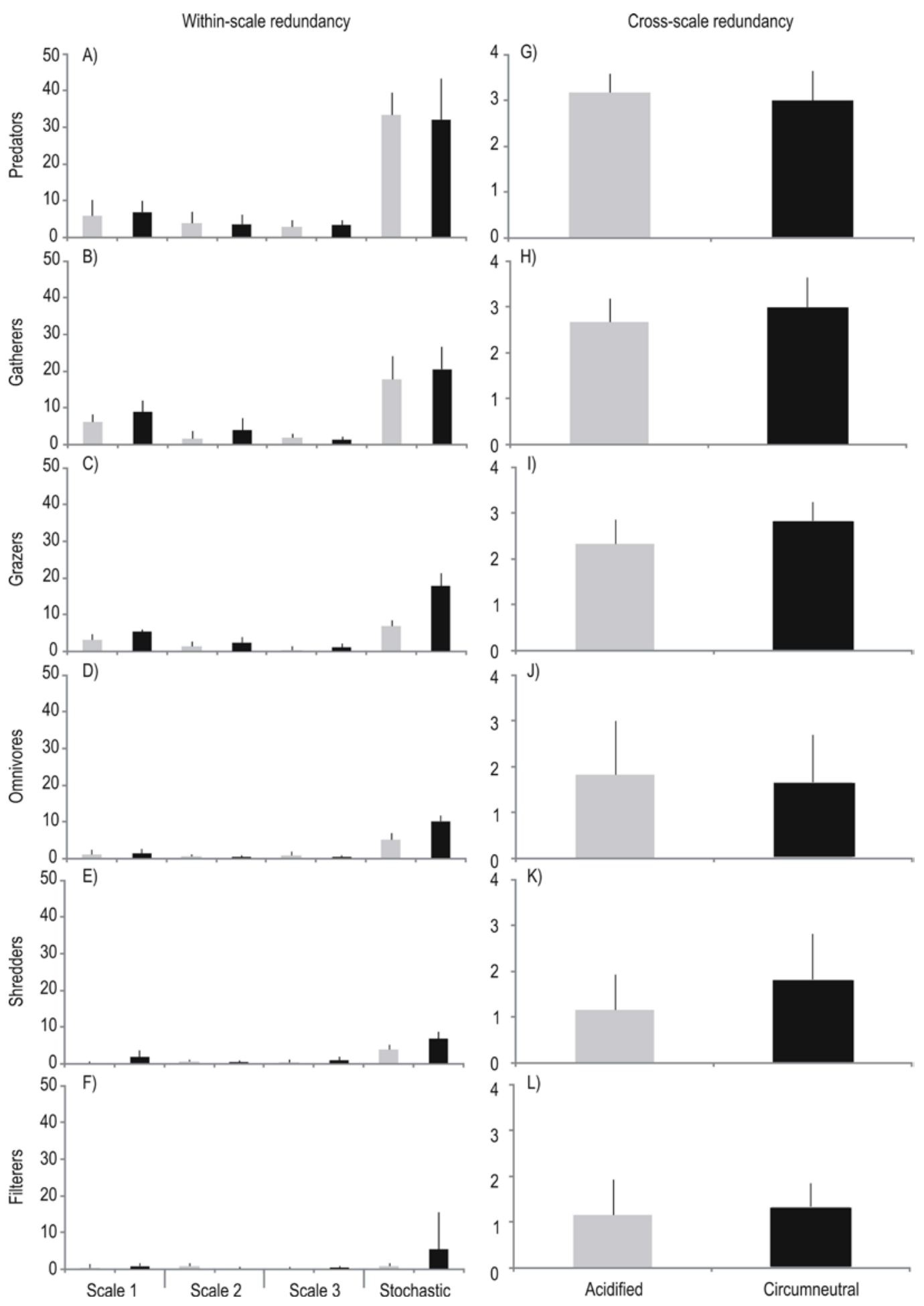


Fig. 5

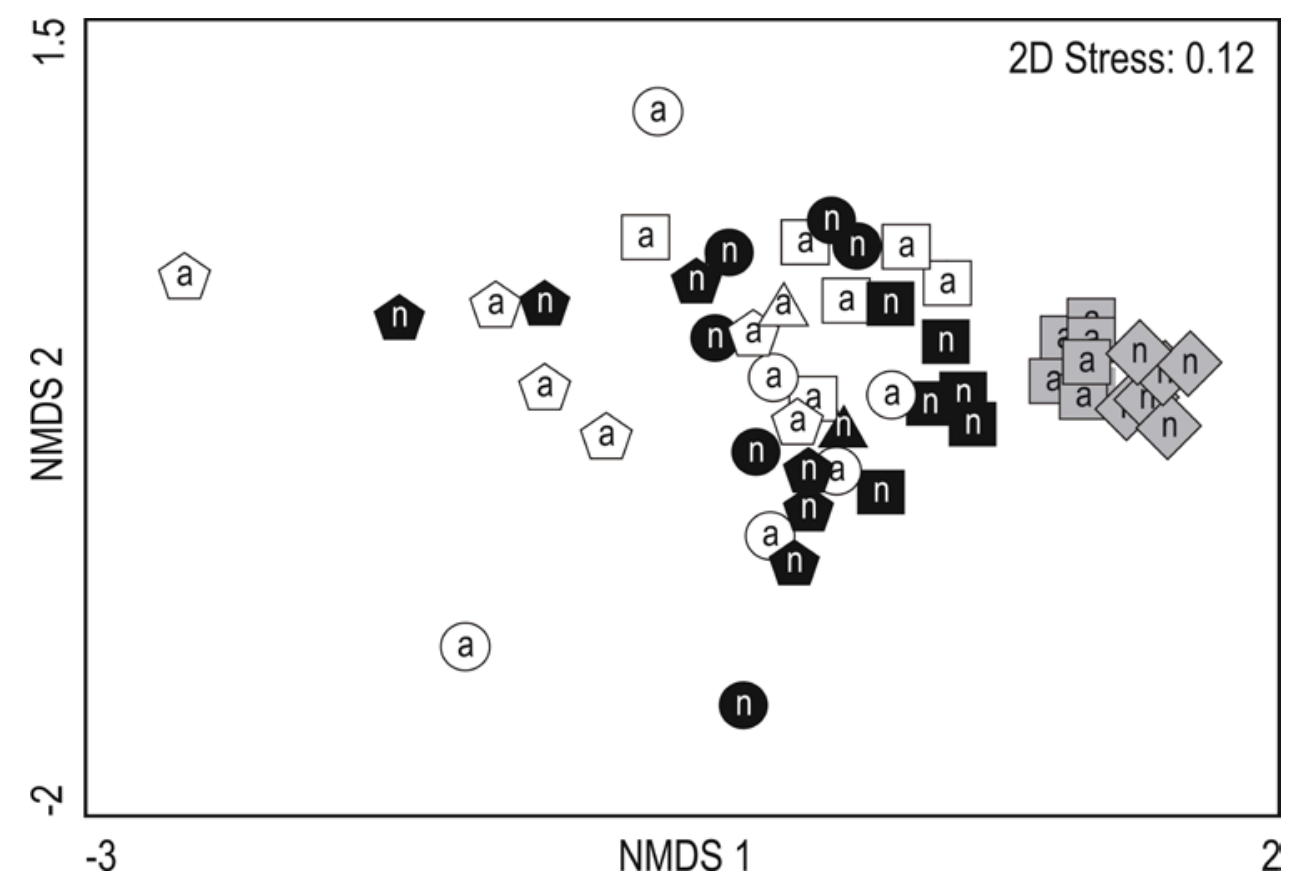

